\title{
Opiniões de usuários de saúde sobre o acolhimento com classificação de risco'
}

\author{
Healthcare clients' opinions regarding the embracement including risk classification
}

Opiniones de pacientes de salud sobre la recepción con clasificación de riesgo

Carine Lais Nonnenmacher ${ }^{1}$, Teresinha Heck Weiller ${ }^{2}$, Stefanie Griebeler Oliveira ${ }^{3}$

\section{RESUMO}

Este estudo buscou conhecer as opiniões dos usuários de saúde sobre o dispositivo de acolhimento com classificação de risco. Trata-se de pesquisa exploratória com abordagem qualitativa realizada com usuários de saúde de um município no Sul do Brasil. A coleta de dados ocorreu por meio de entrevista grupal, realizada com dois grupos: uma com usuários de uma unidade básica de saúde com estratégia de saúde da família e outra com usuários de unidade básica de saúde convencional. Os encontros foram gravados e, posteriormente, as falas foram transcritas e analisadas. Os usuários, dos dois grupos, relataram a ocorrência de conflitos com a implantação do acolhimento com classificação de risco, uma vez que as unidades básicas de saúde distribuem fichas de atendimento por ordem de chegada. O estudo revela que este dispositivo tem potencial para modificações na atenção de saúde desde que se realizem pactos permanentes entre serviços de saúde e usuários.

Descritores: Acolhimento; Triagem; Atenção Primária à Saúde; Organização e Administração; Enfermagem.

\section{ABSTRACT}

The aim of this study was to identify the opinions of healthcare clients regarding the embracement device including risk classification. This exploratory, qualitative study was performed with healthcare clients residing in a city in Southern Brazil. Data were collected through group interviews, which included two groups: one with clients from a primary healthcare unit associated with the family health strategy, and the other with clients of a conventional primary healthcare unit. The meetings were recorded and the discussions were later transcribed and analyzed. The clients from both groups reported the occurrence of conflicts regarding the implementation of the embracement device including risk classification, because the primary healthcare units hand out service forms according to the order in which the clients arrive at the unit. The study shows that this practice has the potential to promote changes in healthcare, provided that agreements are established and understood between healthcare services and clients.

Descriptors: User Embracement; Triage; Primary Health Care; Organization and Administration; Nursing.

\section{RESUMEN}

Se buscó conocer las opiniones de pacientes de salud sobre el dispositivo de recepción con clasificación de riesgo. Investigación exploratoria con abordaje cualitativo, realizada con pacientes de salud de municipio del sur de Brasil. Datos recolectados mediante entrevista grupal, dividida en dos grupos: uno integrado por pacientes de unidad básica de salud con Estrategia Salud de la Familia y otro por pacientes de unidad básica de salud convencional. Los encuentros fueron grabados, transcriptos y analizados. Los pacientes de ambos grupos relataron la ocurrencia de conflictos con la implantación de la recepción con clasificación de riesgo, toda vez que las unidades básicas de salud distribuyen fichas de atención por orden de llegada. El estudio revela que este dispositivo tiene potencia para modificaciones en la atención de salud siempre y cuando se efectúen convenios permanentes entre servicios de salud y pacientes.

Descriptores: Acogimiento; Triaje; Atención Primaria de Salud; Organización y Administración; Enfermería.

\footnotetext{
'Trabalho de Conclusão de Curso de Enfermagem da Universidade Regional do Noroeste do Estado do Rio Grande do Sul.

${ }^{1}$ Enfermeira. Enfermeira do Hospital Nossa Senhora da Conceição de Porto Alegre. Porto Alegre, RS, Brasil. E-mail: carinelais@yahoo.com.br.

2 Enfermeira, Doutora em Enfermagem. Professora Adjunta da Universidade Federal de Santa Maria. Santa Maria, RS, Brasil. E-mail: weiller2@hotmail.com.

${ }^{3}$ Enfermeira, Mestre em Enfermagem. Discente do Programa de Pós-Graduação em Enfermagem da Universidade Federal do Rio Grande do Sul. Porto Alegre, RS, Brasil. E-mail: stefaniegriebeler@yahoo.com.br.
} 


\section{INTRODUÇÃO}

Com a implantação do Sistema Único de Saúde (SUS), um conjunto de políticas e estratégias foi formulado nas duas últimas décadas para a superação de dificuldades existentes no processo de consolidação desse sistema. Dentre elas, a institucionalização da Política Nacional de Humanização (PNH) coloca-se com o desafio de implantar instrumentos técnicos, gerenciais e éticos para a garantia do acesso e da integralidade da atenção aos usuários nos serviços de saúde. Dentre os dispositivos ofertados pela PNH, o Acolhimento com Classificação de Risco (ACR) constitui-se em uma ferramenta para transformação das ações tecnoassistencial, almeja atender a todos os que buscam os serviços de saúde, acolhendo suas necessidades, assumindo uma postura ética que tem, no acolhimento e na escuta, instrumentos para pactuação de respostas mais adequadas aos usuários ${ }^{(1)}$.

Este modelo de receber/acolher indivíduos permite avaliar riscos, definindo prioridade para o atendimento tendo em vista o potencial de gravidade ou de agravamento da queixa apresentada. Mais que uma forma de organizar a porta de entrada de um serviço, é, antes de tudo, uma postura ética para com a vida da cada usuário que a busca.

$O$ acolhimento modifica o processo de trabalho na medida em que propõe inverter a lógica de organização e o funcionamento do serviço de saúde, tomando como princípios o atendimento de todas as pessoas que buscam os serviços de saúde, garantindo a acessibilidade universal; a reorganização do processo de trabalho, deslocando seu eixo central do médico para o trabalho de uma equipe multiprofissional; e a qualificação da relação trabalhador-usuário, a partir de parâmetros humanitários de solidariedade e de cidadania(2).

Esta nova forma de organizar a entrada nas distintas portas do sistema pode produzir nos usuários e trabalhadores, em um primeiro momento, a não distinção entre acolher e triar. Destaca-se que acolher é atender a todos os usuários, conhecê-los, escutar suas demandas e motivos de busca pelo serviço de saúde, bem como significa thes dar boas-vindas, para estabelecer uma relação de confiança ${ }^{(3-4)}$. Triagem, por sua vez, define-se por seleção, escolha conforme critérios de inclusão e exclusão(5), não atendendo, assim, a todos os indivíduos e as suas necessidades, sua singularidade, diferentemente da perspectiva do acolhimento.

O acolhimento constitui-se em um dispositivo capaz de reorganizar o trabalho nos espaços de produção de saúde, ou seja, como uma etapa do processo, ou como uma postura em relação ao usuário e suas necessidades, realizada de forma contínua em todos os momentos de produção de saúde(6).

A classificação de risco, diferente da proposta de acolhimento, foi utilizada inicialmente como um método para realização de triagem e, no Brasil, ela é ainda uma proposta recente, datada de $1993^{(7)}$. A evidência de que essa tecnologia de assistência trouxe benefícios aos serviços e usuários incitou portas de entrada do sistema de saúde a implantá-la, especialmente em hospitais, configurando-se em um dispositivo essencial para a efetivação da PNH. É importante salientar que, diferentemente do que ocorre em muitos países, a classificação de risco no Brasil é vinculada ao conceito e prática de acolhimento, distanciando-se da classificação usualmente tida com o objetivo de triar usuários, conforme já abordado.

A metodologia que orienta a classificação do risco em serviços de saúde segue orientações validadas pelo Ministério da Saúde ${ }^{(1)}$, sendo facultado aos serviços de saúde, a partir dessas diretrizes, elaborarem protocolos de classificação de risco. Dessa forma, em geral, os usuários são avaliados e classificados com as cores: vermelho, amarelo, verde e azul, as quais indicam o grau de risco, conforme o encontrado na avaliação de dados protocolados.

Alguns estudos realizados demonstram como os profissionais de saúde estão sentindo e significando a implantação do ACR. Grande parte desses estudos foram realizados com a equipe de enfermagem ${ }^{(8-10)}$ e trazem considerações acerca das potencialidades e fragilidades do ACR.

Diante disso, considerando que a implementação do ACR afeta a equipe atuante nesse espaço e também os usuários de saúde, considerando que a sua entrada no serviço sofre modificações radicais em relação ao que usualmente estavam habituados, distanciando-se das práticas centradas no médico, onde o seu acesso era definido por filas e ordem de chegada, acredita-se que essa pesquisa preenche de alguma forma as lacunas dos estudos realizados, uma vez que deu voz aos usuários da 
rede de saúde para expressarem suas opiniões sobre o ACR.

Somando-se a isso, em decorrência da participação de um dos autores na implantação do ACR em um pronto atendimento de um hospital do interior do Estado do Rio Grande do Sul/RS, tem-se como objetivo desse estudo conhecer as opiniões dos usuários de saúde sobre o dispositivo de Acolhimento com Classificação de Risco. Tal pesquisa tem sua relevância, sobretudo, pela possibilidade de conhecer como os usuários do sistema que buscam os serviços de saúde percebem o $A C R$, apontando suas potencialidades e fragilidades, o que proporciona reflexões para o planejamento e implementações dessas estratégias.

\section{MÉTOdOS}

Trata-se de uma pesquisa exploratória, de abordagem qualitativa realizada junto a usuários da rede pública de saúde de um município do interior do RS. A escolha pela pesquisa exploratória justifica-se por ela permitir que sejam considerados os mais variados aspectos relativos ao fato estudado ${ }^{(11)}$.

A rede de atenção à saúde neste município é constituída por 25 centros de saúde/unidades básicas, três hospitais e um centro de atenção psicossocial. Atualmente, existem 11 unidades com Estratégia de Saúde da Família (ESF) e as demais compreendem Unidades Convencionais de Saúde (UCS). No município estudado não existe unidade própria de pronto atendimento, dessa forma, os usuários da rede pública de saúde são referenciados para o Pronto Atendimento (PA) de um hospital geral, contratualizado com o SUS, referência para as equipes das ESF e UCS nas situações de urgência e emergência; e, quando essas unidades básicas se encontram fechadas, os usuários acessam diretamente esta porta de entrada para demandas de complexidades diversas.

O Acolhimento com Classificação de Risco foi implantado no pronto-atendimento desse hospital a partir de um projeto estabelecido entre o hospital e o curso de graduação de enfermagem da universidade local, em janeiro de $2008^{(12)}$. Até a implantação do ACR no referido PA, não havia no serviço em questão nenhum critério de acolhimento da demanda do usuário por profissionais de saúde.
O fluxo do serviço era definido por funcionários administrativos, por ordem de chegada, mediante as queixas manifestas $^{(12)}$. Com a instituição do dispositivo, o atendimento nessa porta de entrada passa a demandar o envolvimento de outros núcleos profissionais para além do médico, na acolhida e atendimento desse usuário, e o critério definidor da ordem de atendimento não mais é a ordem de chegada ao serviço, mas é estabelecido mediante critérios próprios para a avaliação do risco apresentado pelo usuário.

Com a instituição do ACR, o atendimento assume a seguinte dinâmica: após preenchimento do boletim de atendimento na recepção, o usuário é avaliado por um acadêmico de enfermagem, o qual, seguindo o protocolo de grau de risco, classifica o paciente com a cor correspondente a sua gravidade, determinando assim a prioridade de atendimento. Os acadêmicos em questão foram previamente selecionados como bolsistas voluntários, de forma a completar uma escala de trabalho mensal que garantia cobertura às 24 horas, intercalando suas atividades de bolsista com as do curso de graduação. Foram capacitados para uso do protocolo de ACR e sobre a dinâmica do processo e são acompanhados por professores da instituição de ensino envolvida, bem como, enfermeiros, médicos, psicólogos do hospital, responsáveis pelas atividades.

Depois da avaliação, o usuário que não apresenta risco de vida aguarda a consulta médica, que é realizada seguindo a ordem de risco previamente estabelecida. Por conseguinte, o usuário recebe a conduta terapêutica estabelecida pela equipe de profissionais do serviço. Excluem-se aqui as situações emergentes, as quais adentram o serviço por uma porta preferencial, recebendo atendimento imediato da equipe de saúde e sendo realizadas as demais ações da equipe em caráter de emergência.

Conforme já descrito, no município em questão há duas modalidades de organização das Unidades Básicas de Saúde (UBS). Um conjunto de unidades oferta os serviços de saúde na modalidade tradicional, a partir do estabelecimento do número diário de atendimentos (fichas), e são denominadas de Unidades Convencionais de Saúde (UCS). A segunda modalidade de organização se faz a partir da conformação de equipes de Estratégia de Saúde da Família (ESF). 
Assim sendo, para este estudo optou-se pela constituição de dois grupos com os usuários, um de cada modalidade de organização de unidade básica, para a participação na pesquisa, a fim de conhecer as opiniões dos mesmos sobre o ACR implantado na porta de entrada do hospital de referência para a rede pública de saúde.

A captação dos participantes pertencentes a uma ESF ocorreu por meio dos agentes comunitários de saúde (ACS), que, informados sobre o objetivo do estudo, realizaram o contato com os usuários de suas microáreas, convidando-os a participar do estudo. No momento do convite, foi expresso que o usuário deveria ter usado o serviço do PA do hospital que instituiu o ACR nos últimos seis meses.

No segundo grupo, formado com usuários da UCS, o contato foi feito a partir da associação de moradores do bairro, que os convidou para uma reunião, na qual foram discutidas as questões da pesquisa. Assim, a composição dos grupos se fez de forma espontânea, tendo, como critério de inclusão, ter utilizado os serviços do PA do hospital nos últimos seis meses.

Para a coleta dos dados, realizada no mês de março de 2009, foi utilizada a técnica de entrevista grupal. Esse tipo de técnica é adequada à abordagem de grupos sociais atingidos coletivamente por fatos ou situações específicas $^{(13)}$. Os encontros tiveram duração média de duas horas e foram gravados.

Posteriormente, essas falas foram transcritas e analisadas, e as gravações apagadas. $O$ instrumento de entrevista foi composto das seguintes questões: 1) Você ou algum de seus familiares já foram atendidos junto ao Pronto Atendimento (PA) do hospital? Como foi este atendimento? 2) Vocês perceberam mudança no atendimento prestado nos últimos seis meses (2008)? 3) Quais são as opiniões/o que acham sobre essa nova forma de atendimento (Acolhimento com Classificação de Risco) junto ao PA? 4) Como você(s) pensa(m) que este serviço deveria ser organizado? Participaram da pesquisa 11 usuários da rede pública de saúde. O grupo formado na ESF foi composto por seis participantes, e o da UCS foi constituído por cinco.

A análise dos dados se desenvolveu por meio da análise temática ${ }^{(14)}$. Ela é dividida em três etapas: a préanálise; a exploração do material; e o tratamento dos resultados obtidos e interpretação. Na primeira etapa, de pré-análise, elaboram-se indicadores que orientam a compreensão do material e interpretação final por meio da leitura flutuante, para constituição do corpus. Já a exploração do material visa alcançar o núcleo de compreensão do texto por meio da formulação de categorias. Nessa etapa, busca-se encontrar nas falas as expressões ou palavras que constituem as ideias centrais do texto. Na última etapa, de tratamento dos resultados obtidos e interpretação, realizam-se inferências nos dados obtidos pelos registros, inter-relacionando com a revisão bibliográfica ${ }^{(14)}$.

Conforme os princípios éticos e respeitando a Resolução 196/96(15), os participantes receberam informações sobre o estudo e assinaram o Termo de Consentimento Livre e Esclarecido. A pesquisa só foi executada após aprovação pelo Comitê de Ética em Pesquisa da Unijuí, com registro no Sistema Nacional de Cadastro de Pesquisa com Seres Humanos, CAAE $n^{\circ}$ 014/2009.

Рага preservar o anonimato dos participantes, as falas dos entrevistados foram identificadas por meio da utilização das letras EG (Entrevista do Grupo), com um número acoplado para identificar se era o grupo 1 ou 2. O número 1 corresponde ao grupo formado por usuários da ESF. E o número 2, ao grupo formado por usuários da UCS. Além disso, adicionou-se um número subscrito que indica cada participante que ia expondo sua opinião no grupo, de forma sequencial (Exemplo: EG1 $1_{01}, \mathrm{EG2}_{01}$, EG102...).

\section{RESULTADOS E DISCUSSÃO}

Após a análise dos dados, foram organizadas duas categorias denominadas, sendo Acolhimento com classificação de risco: espera e conflitos; e Fragilidades na comunicação entre os envolvidos no acolhimento com classificação de risco.

\section{Acolhimento com classificação de risco: espera e conflitos}

Para referirem-se ao $A C R$, os usuários utilizavam o que thes era visual no $A C R$, isto é, os círculos, os quais são representações gráficas com cores correspondentes à classificação do grau de risco da situação apresentada pelo indivíduo. Esses círculos, no entendimento desses usuários, dificultavam o atendimento, gerando descontentamento com a implantação do dispositivo, 
pois foi referido que anteriormente havia percalços e, na atualidade, mais entraves. Essa perspectiva pode ser vislumbrada nas seguintes falas:

\section{Essas bolas aí, tá loco! Nada a ver! (EG101);}

Se antes era já era meio ruim, [com] as bolas agora de cor, ficou pior ainda! (EG102)

As falas refletem a dificuldade encontrada pelos usuários na implantação do ACR, tanto da ESF quanto da UCS, que estão condicionados, habituados a acessar as diferentes portas de entrada da rede por ordem de chegada. Mesmo a ESF, que deveria funcionar de outra forma, permanece com a organização de distribuição de fichas por ordem de chegada.

Nesse sentido, tanto os usuários do grupo 1, quanto do grupo 2, embora pertencentes a unidades básicas, que teoricamente deveriam funcionar com modelos diferentes, representaram o ACR da mesma forma. Esse modelo de organização da atenção condiciona o usuário dos serviços a uma lógica perversa, na medida em que é condição para a obtenção do atendimento sua permanência em uma ou em várias filas. Também pode estar revelando a baixa assimilação/comunicação das informações que o serviço realizou no ano de implantação do ACR junto à população.

Além disso, esta modalidade de acolhimento só foi possível ser implantada em apenas uma porta de entrada do sistema de saúde do município(12), gerando, assim, concepções e sentimentos distintos entre os usuários. Em todas as outras portas de entrada (UBSs com ou sem ESF) o acesso se dá mediante a ordem de chegada ao serviço e com um número pré-estabelecido de atendimentos. Entretanto, ao adentrar o PA do hospital de referência, o usuário depara-se com um modelo distinto daquele com que está habituado, suscitando expectativas, anseios e dúvidas quanto ao novo sistema(12). Assim, observa-se que as estratégias que visam reorganizar a atenção à saúde pensadas fora da rede, de forma isolada das demais práticas de produção de saúde, proporcionam que o dispositivo se transforme em um instrumento a ser implantado perdendo sua potência de transformação das práticas ${ }^{(16)}$.

Diante disso, acredita-se que a implantação do ACR deve ser discutida amplamente com todos os atores envolvidos, tais como os gestores, profissionais de saúde e usuários, dentro da rede, e não de forma isolada em apenas um dos serviços de saúde, contribuindo para a qualificação da rede como um todo.

É possível perceber também, nas falas dos entrevistados, a falta de informação quanto à função e o funcionamento do ACR por parte dos indivíduos, conforme pode ser ilustrado na fala a seguir:

Mas, daí, botaram ela sentada e lá ela ficou esperando a vez da bola, amarela, azul e roxa, sei lá o que houve. [...] Eu acho, assim, que eles deviam dar prioridade pra quem precisa mesmo [...], mas tem gente, às vezes, lá, quase morrendo, ficam um dia inteiro lá sentados porque têm que esperar a cor da bola. É por bola, cor preta, vermelha, azul, não sei que cor lá... Eu acho isso o fim da picada! (EG101)

Apesar de ter ocorrido divulgação prévia à implantação do ACR no referido hospital, via diferentes meios de comunicação (jornal, rádio, cartazes, palestras, reuniões com lideranças da comunidade), parece aqui que ainda havia desconhecimento e muitas dúvidas quanto ao uso dessa tecnologia. A falta de informação, além de gerar insatisfação do usuário e conflitos entre os mesmos e os trabalhadores, impede a abertura do sujeito a novas formas de produzir cuidado e, ainda, o exclui da construção coletiva do sistema.

Diante disso, evidencia-se a necessidade constante de discussão do ACR, a fim de que este possa ser pensado, construído e planejado por todos os envolvidos nos cenários de produção de saúde. Assume relevância na propositura de mudanças do modelo assistencial a participação do controle social. Normalmente, gestores, trabalhadores e instituições formadoras pensam as políticas, as ações a serem operadas, e não incluem os usuários nessa construção. A fala dos usuários traduz o não reconhecimento, a não participação deles na operacionalização, na mudança de procedimento que o ACR passa a demandar dos diferentes sujeitos/atores nas portas de entrada da rede.

Esta visão reducionista do acolhimento termina por configurá-lo em um dispositivo utilizado apenas para reorganizar o trabalho na unidade, conformando-o, desse modo, como uma etapa do processo e não uma postura contínua nos modos de produzir saúde ${ }^{(6)}$. Ainda, tal visão acaba por não imprimir mudanças no sistema de 
saúde local, configurando o ACR como uma ação isolada dentro da rede, com limites que impedem sua expansão aos demais serviços, o que pode ser identificado na discordância da implantação do ACR na rede por parte da maioria dos entrevistados.

Conhecer como os usuários avaliam o atendimento a eles prestado permite repensar as práticas profissionais ou intervir sobre a forma de organização dos serviços, visando seu aperfeiçoamento. Esta consideração do usuário como protagonista do sistema de saúde tem impacto direto na melhoria da relação entre ele e o serviço(17).

Outro fator que gera insatisfação aos usuários do SUS refere-se ao fato de o PA priorizar o atendimento dos indivíduos que possuíam planos privados de saúde, ferindo, dessa forma, os princípios éticos que sustentam a proposta do ACR, no cenário da Política Nacional de Humanização da Atenção em Saúde. Esse fato contribui para a rejeição ao dispositivo, pois este parece servir apenas a alguns indivíduos, os usuários do SUS. Vislumbra-se esse aspecto na fala abaixo:

Claro que, se chegar alguém todo quebrado, todo, dai, claro, tem que passar na frente. Mas não ser assim, quem tem convênio passar na frente. (EG102)

A fala do usuário reflete uma realidade vivenciada no SUS na maioria absoluta dos municípios brasileiros. Como o sistema público não tem capacidade instalada suficiente e resolutiva nos níveis da atenção básica e de média densidade tecnológica, tem suprido suas faltas por meio da compra de serviços junto a instituições privadas. Essas por sua vez, vendem seus serviços para operadoras privadas de planos de saúde.

Mesmo o sistema público, via SUS, sendo hoje o maior comprador e financiador das instituições privadas/filantrópicas, ainda são frequentes as denúncias de que os usuários do SUS são preteridos no atendimento, independente do risco que apresentam. No hospital estudado, o usuário identifica essa situação, denuncia na sua fala que o critério de prioridade em uma porta de entrada hospitalar sempre deve ser o risco, não a modalidade de convênio.

Por outro lado, na medida em que se analisa o ACR implantado no PA, isto é, quando se reflete acerca dos princípios do dispositivo em questão, identifica-se na fala dos usuários certa aposta e reconhecimento nos princípios que regem essa estratégia. Nessa perspectiva, a fala a seguir revela a concordância dos usuários com a principal ação do ACR em prontos atendimentos, reconhecendo que o critério do risco deva ser o ordenador da assistência:

Eu acho, assim, quem tá mal, que a pessoa vê que tá mal, os médicos lá, as enfermeiras, tudo veem que a pessoa tá mal, tem que ser atendido antes. Eu acho certo isso. (EG104)

O ACR, de fato, otimiza o atendimento dos indivíduos em maior situação de gravidade, não excluindo a demanda espontânea do serviço de urgência e emergência. Além disso, experiências com a implantação dessa estratégia demonstram que esse modelo possibilita informar ao usuário a expectativa de atendimento e o tempo de espera, diminuindo-lhe a ansiedade e aumentando-lhe o nível de satisfação(10).

Por mais de 40 anos o atendimento do PA do hospital do município estudado foi organizado por ordem de chegada ao serviço. A prática usual era de que o usuário preenchia seu boletim junto aos serviços de recepção e aguardava pela consulta médica, não havendo nenhuma ponderação quanto aos diferentes graus de risco daqueles que ali aguardavam.

A confiança, satisfação e aposta real dos usuários no dispositivo somente poderão ser conquistadas na medida em que houver alterações na dinâmica do processo de trabalho local, levando em consideração o preconizado pelo Ministério da Saúde (MS) no que tange ao ACR. Essas alterações abrangem tanto o processo de trabalho como os trabalhares e gestores locais, e envolvem, além das mudanças organizacionais, a mudança de posturas éticas.

\section{Fragilidades na comunicação entre os envolvidos no acolhimento com classificação de risco}

A introdução de uma nova metodologia de organização da demanda na porta de entrada não produz modificações significativas para os usuários. Estes manifestam seus descontentamentos, verbalizando que suas queixas/demandas que no modelo anterior era feitas a um único profissional (médico), e agora passam a ser feitas para dois, isto é, ao acadêmico de enfermagem 
e ao médico, em dois momentos distintos. Acompanhemos o que nos diz EG202:

Não, tu fala os dois tempos a mesma coisa, porque tu tem que explicar pro avaliador tudo, e depois, quando vem $o$ médico, tu reexplica tudo de novo. Tu tem que dizer pro avaliador tudo o que tu tem, pra ele te contabilizar nas bolinhas, lá (risos).

Nota-se que o usuário ainda tem dificuldades para reconhecer a metodologia como inovação para qualificar a assistência recebida, não distingue o dispositivo de ACR como uma estratégia para produzir saúde, passando para ele a noção de uma etapa desnecessária. Também são reveladas na fala as fragilidades no processo de trabalho da(s) equipe(s) de ACR, podendo ser remetidas à dificuldade de comunicação na equipe, ou à falta de confiança dos profissionais na avaliação feita por outro colega.

A partir disso, acredita-se que a equipe deveria avaliar a forma como está conduzindo o acolhimento, pois o indivíduo não pode ser submetido a falar repetidas vezes suas queixas e história. A organização do ACR deve perpassar pelo enfermeiro que acolhe o usuário, que registra suas queixas, e o classifica conforme seu risco apresentado. Por conseguinte, essas informações registradas podem ser transmitidas ao profissional médico, retirando a necessidade de o indivíduo contar novamente suas demandas ${ }^{(10)}$.

Outro elemento apontado por usuários diz respeito à atuação da enfermagem, no estudo, representada por acadêmicos, ao afirmarem que estes não têm legitimidade para avaliar risco. Manifesta-se EG104:

Uma criança que não sabe dizer o que dói, tá com febre, tá com tosse, mas não sabe dizer o que dói, daí eles examinam assim, as estagiárias examinam. O que uma estagiária vai saber de uma criança que tá com uma febre? (EG104).

A fala revela mais uma vez que o modelo hegemônico que orienta a ação dos usuários quando adentram uma porta de serviços de saúde ainda é pautado na avaliação do médico. Revela o quanto ainda os profissionais do campo da saúde, especialmente o enfermeiro, no espaço hospitalar, tem baixo reconhecimento social de seu conhecimento técnico/científico. Diante disso, reflete-se sobre o longo caminho que a enfermagem tem que percorrer na sociedade brasileira para garantir a integralidade da atenção. E que a atenção não é propriedade de apenas um núcleo profissional. Que o adoecimento, no século XXI, está revelando aos profissionais do campo da saúde, e logo irá despertar nos usuários, o entendimento de que a produção do cuidado no campo da saúde é essencialmente interdisciplinar.

Destaca-se sobre o ACR que, mesmo após sua implantação, a sua efetivação depende de um permanente diálogo entre os atores, pactuações e repactuações, a fim de consolidar um modelo de atenção que responda às reais necessidades dos usuários, trabalhadores e dos gestores públicos junto à rede de atenção de saúde. Juntamente com a forma de organização do serviço, é preciso que se converse cotidianamente sobre o protocolo com os usuários, já que a classificação é norteada por um protocolo préestabelecido(10). Vale destacar que foram realizados capacitações para a inserção dos acadêmicos de enfermagem, habilitando-os para realizarem o $A C R$, construindo um caminho de diálogo com os profissionais da unidade (médico e enfermeira, técnicosadministrativos) para que o acolhimento fosse introjetado nas práticas de todos os trabalhadores.

Em um estudo(18) realizado com usuários, mostra-se a dificuldade deles para aceitar o atendimento inicial por um enfermeiro, além de caber a esse profissional a decisão de serem atendidos pelo médico. Essa perspectiva remete-se à permanência do modelo hegemônico, centrado no médico, o qual pode ser progressivamente modificado, na medida em que se discuta e incorpore na atenção à saúde os princípios e diretrizes preconizadas pelo o SUS.

A relação entre profissional e usuário apresenta-se fragilizada no olhar dos participantes da pesquisa, decorrentes do frágil vínculo que tem a equipe de trabalhadores do PA com o usuário, revelados quando da falta de escuta às demandas individuais. Esse aspecto, presente anterior e posteriormente à implantação do ACR, dificulta a construção de vínculo, gerando insatisfação quanto à clínica prestada pelo profissional de saúde: 
Eu não concordo, porque as enfermeiras examinam ali, dai olham, tiram a febre, daí o doutor nem encosta na criança, nem encosta na pessoa, já diz. Daí ele, o doutor encostando, examinando com aquele [estetoscópio], ele já vê mais ou menos como que tá o coração, e as enfermeiras olham e depois elas só escrevem ali, e o doutor olha e dá a receita, e deu! Ele não examina a garganta, não examina nada. [...] [Antes do acolhimento] Ele [médico] só explicava, mas não examinava também, não ele, eles. Ele te olhava, tá sentindo isso, tá sentindo aquilo, ou a criança tava assim, ele só olhava e receitava, e deu! Agora que a gente fica direto com a enfermeira, dai ele nem... a diferença é que ele não olha mais a gente. (EG102).

O usuário, ao referir a inexistência de vínculo entre a população e os profissionais que atuam no PA, identifica que o estabelecimento de vínculo é frágil, decorrente do processo de trabalho que historicamente está pautado na lógica da queixa/conduta. Romper com essa lógica requer da rede de saúde o estabelecimento efetivo de pontos de conexão que viabilizem a transferência do usuário, bem como a responsabilização sanitária deste.

O desafio para as redes de atenção de saúde está na definição e conformação de linhas de cuidados que assegurem que o usuário sempre tenha na retaguarda do acompanhamento de sua necessidade de saúde uma equipe de referência. Esta, preferencialmente vinculada ao território onde os usuários do sistema público estão adscritos. Nesse sentido, a atenção básica, especialmente as unidades convencionais e/ou a ESF, assumem a responsabilidade do acompanhamento longitudinal do quadro dos usuários. O PA constitui-se em importante porta na rede que tem especificidade na garantia da integralidade da atenção, no entanto, não substitui o lugar e a responsabilidade das UCS e das ESF.

Outro estudo, realizado com profissionais de enfermagem que atuam no acolhimento com classificação de risco, demonstra que estes sofrem muito na execução de seu trabalho, uma vez que compreendem que a sua intervenção junto ao usuário é desprovida de resolutividade e o seu fazer parece não ter sentido. Esse dado traz um alerta à equipe de enfermagem, que atua com a tarefa de acolher e reorientar o fluxo de atendimentos no pronto-socorro, sob riscos de reforçarem as fragilidades do sistema de referência e contrarreferência em saúde, do ponto de vista institucional, e de causarem dano à própria saúde devido à falta de motivação( ${ }^{(8)}$.

Atualmente, com o desenvolvimento de novas técnicas na área da medicina, tem-se denotado um papel mais importante as tecnologias no exercício da profissão, em detrimento da relação pessoal entre médico e paciente, deixando-se de lado o aspecto subjetivo dessa relação(19). Essa assertiva não se restringe apenas aos profissionais médicos. Observa-se no cotidiano das instituições de saúde a pouca interação entre os profissionais da saúde e os usuários, sendo o processo de trabalho orientado sob o modelo queixa-conduta.

O encontro entre o paciente e o médico, no momento da consulta, foi outro ponto referido no estudo. A criação de vínculo entre profissional e usuário é uma das estratégias defendidas pelo SUS para prover a humanização dos serviços de saúde, visando aumentar o grau de autonomia e de protagonismo dos sujeitos no processo de produção de saúde, e à elaboração conjunta do projeto terapêutico ${ }^{(1)}$.

Assim, vínculo e acolhimento partilham juntos do intuito de humanizar os serviços. Contudo, com base neste estudo, é possível visualizar uma relação impessoal entre profissional e usuário, um atendimento baseado no modelo biomédico, mecanicista, atuante sob o modelo queixa-conduta, com inexistência de um olhar que visualize um indivíduo doente, e não apenas um sistema ou órgão com uma doença.

\section{CONSIDERAÇÕES FINAIS}

Os dados do estudo expressam que o ACR, estando presente em apenas uma única porta de entrada da rede de saúde, não conseguiu provocar alterações na rede de atenção, especialmente na atenção básica, no que tange aos modos de produzir saúde, não sendo reconhecido pelo usuário como uma estratégia de inovação do sistema. Pelo contrário, observou-se o descontentamento dos usuários tanto de ESF quanto de UCS em relação ao ACR, pois eles estão acostumados com a organização sob a forma de distribuição de fichas por ordem de chegada. No local estudado, tal dispositivo conseguiu apenas tipificar a demanda, não tendo conseguido acolher seus usuários, na medida em que não se garante que suas necessidades serão sanadas, resolvidas. 
Acredita-se, que a discussão entre gestores e trabalhadores do serviço quanto aos fatores éticos, função e funcionamento do ACR também é uma ação necessária, já que foi possível perceber nas falas que o mesmo apenas está organizando o trabalho do profissional médico, sem promover mudanças na forma de produzir saúde nesse espaço e nas demais portas de entrada da rede de atenção em saúde. O ACR, nesse espaço, infelizmente, acabou por fortalecer a diferenciação social e a desresponsabilização do PA para com o usuário, uma vez que este não é encaminhado para a equipe de referência da unidade básica de saúde.

Identificam-se vários apontamentos dos usuários quanto à organização do ACR no PA. Alguns desses nos remetem a convencionalismos vinculados à saúde anterior à criação do SUS, como a presença ainda marcante do modelo médico-hegemônico nas falas dos entrevistados e o não reconhecimento dos demais profissionais no processo de produção da saúde. Esses apontamentos exigem espaços de conversação com os

\section{REFERÊNCIAS}

1. Brasil. Ministério da Saúde. Humaniza SUS: acolhimento com avaliação e classificação de risco: um paradigma ético-estético no fazer em saúde. Brasília (Brasil): Ministério da Saúde, 2004. 48p. 2. Franco TB, Bueno WS, Merhy EE. O acolhimento e os processos de trabalho em saúde: o caso de Betim, Minas Gerais, Brasil. Cad. Saude Publica. [Internet]. 1999[cited 2008 set 18];15(2):345-53. Available from: http://www.scielo.br/pdf/csp/v15n2/0319.pdf

3. Coelho MO, Jorge MSB. Tecnologia das relações como dispositivo do atendimento humanizado na atenção básica à saúde na perspectiva do acesso, do acolhimento e do vínculo. Cienc. Saude Colet.2009;14Suppl.1:S1523-31.

4. Martins JJ, Nascimento ERP, Geremias CK, Schneider DG, Schweitzer G, Neto HM. O acolhimento à família na Unidade de Terapia Intensiva: conhecimento de uma equipe multiprofissional. Rev. Eletr. Enf. [Internet] 2008[cited 2011 jan 10];10(4):1091-101.

Available from:

http://www.fen.ufg.br/revista/v10/n4/v10n4a22.htm

5. Pinho LB, Hernández AMB, Kantorski LP. O discurso sobre o acolhimento e a acessibilidade nos serviços comunitários de saúde mental. Cogitare Enferm. [Internet].2009[cited 2010 jun 20];14(4):612-9. Available from:

http://ojs.c3sl.ufpr.br/ojs2/index.php/cogitare/article/viewFile/1637 3/10854

6. Takemoto MLS, Silva EM. Acolhimento e transformações no processo de trabalho de enfermagem em unidades básicas de saúde de Campinas, São Paulo, Brasil. Cad. Saude Publica. [Internet] 2007[cited 2008 set 15];23(2):331-40. Available from:

http://www.scielo.br/pdf/csp/v23n2/09.pdf

7. Grupo Brasileiro de Acolhimento com Classificação de Risco (GBACR) [Internet]. História da Classificação de Risco: no Brasil [cited 2008 nov 13]. Available from:

http://gbacr.com.br/index.php?option=com_frontpage\&ltemid=1 8. Pai DD, Lautert L. Sofrimento no trabalho de enfermagem: reflexos do "discurso vazio" no acolhimento com classificação de risco. Esc Anna Nery. 2011;15(3):524-30.

9. Nascimento ERP, Hilsendeger BR, Neth C, Belaver GM, Bertoncello KCG. Classificação de risco na emergência: avaliação da equipe de enfermagem. Rev. Enferm. UERJ. 2011;19(1):84-8. usuários, a fim de esclarecê-los quanto aos princípios e diretrizes do SUS, quanto a conceitos como trabalho em equipe multidisciplinar, clínica ampliada, a respeito da importância de ações de prevenção e promoção da saúde, dentre outros.

No estudo evidenciou-se que há o reconhecimento por parte dos usuários do ACR como potência restrita, contudo, aos serviços de urgência/emergência. Sendo assim, para efetivação dessa estratégia tanto no PA em questão, quanto para a aposta em sua ampliação aos demais serviços da rede, configura-se como urgente a descontinuação de ações que promovam discriminação entre os sujeitos, de forma a conquistar a confiança dos usuários neste novo modo de produzir saúde.

No nível local, o ACR, por fim, ainda não conseguiu firmar-se como um dispositivo produtor de mudanças na atenção à saúde, o que revela a necessidade de articulação entre os diferentes atores sociais (gestores, profissionais e usuários) de forma a promover a aposta e a construção coletiva desta importante tecnologia.

10. Souza RS, Bastos MRA. Acolhimento com classificação de risco: o processo vivenciado por profissional enfermeiro. REME: Rev. Min. Enferm.[Internet]. 2008[Cited 2010 set 10];12(4):581-6. Available from: http://www.enf.ufmg.br/reme/remev12n4.pdf.

11. Gil AC. Como elaborar projetos de pesquisa. 5th ed. São Paulo: Atlas, 2010.

12. Weiller TH. O acesso na rede pública de saúde no município de ljuí/RS: um cenário de controvérsias [thesis]. Ribeirão Preto: Escola de Enfermagem/USP; 2008. 185p.

13. Lakatos EM, Marconi MA. Fundamentos de metodologia científica. 3. ed. São Paulo: Atlas, 1991.

14. Minayo MCS, Deslandes SF, Neto OC, Gomes R. Pesquisa social: teoria, método e criatividade. 28a. ed. Petrópolis: Vozes; 2009 15. Brasil. Ministério da Saúde. Conselho Nacional de Saúde. Resolução 196/96 [Internet]. Brasília: Ministério da Saúde; 1996 [cited 2008 nov 11]. Available from:

http://www.datasus.gov.br/conselho/resol96/RES19696.htm 16. Santos Filho SB, Barros MEB, Gomes R.S. A Política Nacional de Humanização como política que se faz no processo de trabalho em saúde. Interface - Comunic. Saude. Educ. 2009;13Suppl.1:S603-13. 17. Ramos DD, Lima MADS. Acesso e acolhimento aos usuários em uma unidade de saúde de Porto Alegre, Rio Grande do Sul, Brasil. Cad. Saude Publica. [Internet]. 2003[cited 2009 jan 21];19(1):27-34. Available from: http://www.scielo.br/pdf/csp/v19n1/14902.pdf. 18. Souza ECF, Vilar RLA, Rocha NSPD, Uchoa AC, Rocha PM. Acesso e acolhimento na atenção básica: uma análise da percepção dos usuários e profissionais da saúde. Cad. Saude Publica. [Internet]. 2008[cited 2008 nov 15];24 Suppl.1:S100-10. Available from: http://dx.doi.org/10.1590/S0102-311X2008001300015. 19. Caprara A, Rodrigues J. A relação assimétrica médico-paciente: repensando o vínculo terapêutico. Cienc. Saude Colet. [Internet].2004[cited 2009 maio 21];9(1):139-46. Available from: http://www.scielosp.org/pdf/csc/v9n1/19831.pdf.

Artigo recebido em 04/03/2011. Aprovado para publicação em 14/03/2012. Artigo publicado em 30/09/2012. 